\title{
DOS LITERATOS ARABES VIAJAN POR SHARO AL-ANDALUS: SHAKIB ARSLAN (1939) Y HUSAIN MONES (1963)
}

\author{
Por \\ MIKEL DE EPALZA
}

Los dos textos árabes que se presentan y traducen aquí son correlativos y complementarios. Pertenecen a dos grandes intelectuales árabes modernos, un libanés y un egipcio, que visitan Sharq Al-Andalus y publican, en 1939 y en 1963 respectivamente, sus impresiones de viaje, avaladas por un estudio suficientemente profundo de la historia de España.

En realidad tanto Arslán como Mones visitan Sharq Al-Andalus, no el Levante de la Península. Visitan estas tierras como tierras que fueron árabes y donde floreció la civilización árabe-islámica de Al-Andalus. Son testigos árabes modernos de la presencia permanente, para los árabes pero también para los españoles, de la historia árabe en esta región de la Península lbérica.

No se trata aquí de hacer un estudio sobre estos dos textos ni sobre los libros de los que están extraídos o sobre sus autores. Son simples textos que expresan una realidad de mediados del siglo XX: la visión de dos escritores árabes sobre España y su historia árabe (1).

\section{Shakib Arslán en Alicante}

El Emir (Príncipe) Shakib Arslán (1870-1946) (2) visitó Sharq AlAndalus y en particular Alicante en el verano de 1930. Es un "viaje turístico» que hizo a Al-Andalus, como dice expresamente en su texto $\langle 3\rangle$. Su

(1) Ver, por ejemplo, M. de EPALZA, «España y su historia vista a través de los textos de enseñanza media de Siria», Almenara, Madrid, 2, 1972, 52-108; "L'histoire d'Al-Andalus dans les livres de texte de l'enseignement secondaire», Actas del $/ 1 \circ$ Coloquio hispano-tunecino de historiadores, Madrid, 1973, 117-129; $P$. MARTINEZ MONTAVEZ, "Las relaciones literarias hispano-árabes contemporáneas. Planteamiento del tema", Estudios de Asia y Africa, México, XV/1, 1980, 102-123.

(2) Corrijase esta última fecha, que no es 1930, en P. MARTINEZ MONTAVEZ, Introducción a la literatura ára be moderna, Madrid, 1974, p. 152.

(3) S. ARSLAN, Al-hulal as-sundusiyya fi l-ajbâr al-andalusiyya / Libro "Las lluvias suaves como la seda» sobre noticias acerca de Al-Andalus/, El Cairo, 3 vols., 1936-1939. 
viaje real lo hizo viniendo de Cartagena y tomando luego el trenecito de La Marina, hacia Denia. En cambio en su libro va describiendo la región de Norte a Sur: entra en la provincia de Alicante por el Molinell y Vergel ( $p$. 292) para llegar a Denia -con varias páginas sobre su historia árabe-; sigue con Cocentaina (p. 334), Benissa, Calpe, Altea, Benidorm y Alicante (a la que dedica las páginas 336 a 342, que son las que aquí traducimos).

El texto seguirá con Elche y Orihuela -con menciones a Rocamora y Torrevieja-, para entrar en el reino de Murcia (Segura, Chinchilla, Lorca, Cartagena y Murcia), del que cita una larga lista de topónimos, algunos de época árabe (pp. 405-410).

El texto va acompañado de algunas fotos, concretamente de los paseos de Alicante (de las Palmeras, de la Rambla), que encantaron al Emir Shakib Arslán.

Para comprender mejor esos textos conviene explicar algo sobre la personalidad del autor, sobre su libro y sobre el contenido de su texto sobre la ciudad de Alicante.

\section{El autor de Al-Hulal As-Sundusiyya fî l-Ajbâr al-Andalusiyya}

El Emir Shakib Arslán nació en el Chouf (Ash-Shuwaifât), en las montañas al este de Beirut, en esa región árabe que bajo el Imperio Otomano se llamó la Gran Siria (Ash-Shâm) y, al desmembrarse el Imperio tras la Primera Guerra Mundial, dio origen a cuatro «protectorados» árabes, ocupados bajo la "protección» inglesa (Palestina y Transjordania) y francesa (Siria y Líbano).

El Emir tenía una gran importancia política en la región, por su familia, que aún hasta hoy ejerce un tradicional liderazgo en la comunidad étnicoreligiosa de los drusos, implantados en las montañas de toda la región, por encima de las fronteras políticas artificales del siglo XX. Este origen familiar explica en gran parte su importante actividad política y también sus relaciones con la América hispánica, a donde habían emigrado muchos drusos, después de la ocupación inglesa de Palestina. En Hispanoamérica esos drusos son llamados «turcos», como los demás emigrados árabes

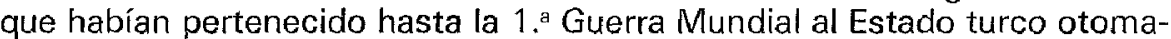
no, y sus descendientes. La comunidad drusa es particularmente numerosa en Venezuela.

Shakib Arslán pertenece también a una importante generación de políticos que se puede definir como nacionalistas árabes, independentistas árabes frente a turcos, europeos y, luego, judios, instalados en Oriente Medio árabe. Se autodesterró a Suiza, para luchar con más libertad y eficacia en favor de la independencia política de los países árabes, junto a la Sociedad de Naciones instalada en Ginebra.

Viajero y publicista, desarrolló una gran actividad a lo largo de su larga vida, en todo el mundo árabe. Por su origen minoritario (druso), se planteó muchos problemas religioso-políticos y se inclinó hacia un cierto laicismo 
estatal árabe, como otros minoritarios siro-palestinos, cristianos y musulmanes. Esta actitud explica su patriótico entusiasmo árabe por Al-Andalus árabe, pero también su interés prioritario por temas culturales, y no por consideraciones teológico-religjosas.

Entre sus trabajos de escritor hay que destacar su labor periodística, en prensa árabe y europea, fundando también un periódico nacionalista en Suiza. Sus libros abarcan desde la edición de escritores árabes (entre ellos la antología de su hermano Nasib) hasta libros nacionalistas (su famoso «Por qué quedaron retrasados los musulmanes y progresaron otros») y sobre sus relaciones con el reformista musulmán egipcio Rashid Ridá. Toca a temas andalusíes especialmente en dos obras: "Historia de las expediciones militares de los árabes por Francia, Suiza, Italia y las islas del Mediterráneo» (1933/1345) y "Anotaciones a Ibn Jaldún» (1936), ambas escritas en árabe. También tradujo «El último Abencerraje» de Chateaubriand.

Pero su obra magna sobre Al-Andalus, que ocupó los quince últimos años de su vida, fue Al-Hulal As-Sundusiyya fíl-Ajbâr al-Andalusiyya.

\section{El libro de Arslán y el texto sobre Alicante}

El libro del Emir Shakib Arslán tiene un título largo, de estilo medieval, con un pareado interno, que separa el nombre poético del libro de su contenido: "Libro "Las lluvias suaves como la seda", sobre noticias acerca de Al-Andalus", semejante al título de un tunecino del siglo XVIII, de origen andalusí (4). Quería ser la más amplia historia de Al-Andalus (5), en 10 volúmenes, de los que sólo se imprimieron los tres primeros: viaje por el norte de la Península, por el centro y por Sharq Al-Andalus (6). El cuarto volumen tenía que ser sobre Córdoba y el conjunto de la actual Andalucía. El tercer volumen, en el que se encuentra el texto sobre Alicante, se acabó de imprimir en El Cairo en agosto de 1933, correspondiente al mes musulmán de Raŷab de 1358.

Por tanto, entre el viaje de 1930 y la aparición del primer volumen en 1936 y el tercero en 1939 pasaron varios años. Los empleó Shakib Arslán, con los medios económicos de que disponía, en recoger apasionadamente material para su obra, labor que prosiguió hasta su muerte en Beirut, de vuelta de un viaje a Egipto, el 9 de diciembre de 1946 (7).

El material que había recogido para su libro comprendía textos árabes antiguos y estudios históricos modernos, junto con guías y enciclopedias de actualidad sobre España y, naturalmente, los apuntes de viaje del propio Arslán. Estas fuentes aparecen claramente en el texto sobre Alicante.

(4) Ver artículo de Mi.A. AL-HILA, «L'élément andalou en Tunisie, selon le "Hulal al-sundusiyya", d'Al-Sarrag Al-Andalusiy, en M. de EPALZA - R. PETIT, Receuil d'études sur les moriscos Andalous en Tunisie, Madrid, $1973,264-266$

(5) Sâmî AD-DAHHAB, Al-amîr Śakib Arslân. Hayâtu-hu wa-âtâru-hu / El príncipe Shakib Arslán. Su vida y sus obras /, El Cairo, 1976 (2." ed.), p. 282, que afirma que el Emir dedicó 40 años de su vida a esta obra.

(6) Todo el volumen $3 .^{\circ}$ está destinado al Sharg Al-Andalus (664 páginas, con ilustraciones e índices).

(7) Sâmî AD-DAHHAB, o.c. pp. 99-100. 
Por eso se nota en el texto de Arslán su curiosidad por los orígenes históricos (toponimia, arqueología) y por los paisajes y datos geográficos, pero sobre todo por los textos árabes medievales sobre la ciudad (el texto fundamental del geógrafo Al-Idrisi, del siglo Xll) y sobre sus personalidades árabes (la información del biógrafo y político valenciano Ibn Al- ${ }^{\mathrm{C}} \mathrm{Abbâr}$. del siglo XIII).

Esta asimilación muy personal -y muy viva- de estos varios elementos, en el caso de Alicante, da el texto sabroso que aquí se traduce y que expresa bien la visión del escritor, intelectual, político y patriota árabe oriental que era Shakib Arslán. En él no se expresa aún su actividad política con el régimen del general Franco, en coordinación con los marroquíes (8).

\section{Husáin Mones}

Hosáin Mones (Husayn Múnis), egipcio, nacido en 1912, es también un escritor polifacético, centrado en su oficio académico de profesor universitario, catedrático de Historia del Isłam en la Universidad de El Cairo. Fue Director del Instituto Egipcio de Estudios Islámicos de Madrid durante 14 años, de 1956 a 1969, durante los cuales participó muy activamente en todas las relaciones culturales hispano-árabes, siendo uno de los árabes que mejor conoce la cultura española, como se demuestra en sus múltiples libros y crónicas periodísticas en revistas y diarios de Oriente Medio.

Ya había visitado España en 1940 y antes de escribir su libro «Viaje por Al-Andalus» (Rihlat Al-Andalus) había estado en Valencia y Mallorca, como lo explica en el capítulo «El ala cortada: Sharq Al-Andalus». Este libro está escrito en marzo de 1963 y se publica en El Cairo a finales del mismo año.

Como escritor, es autor de numerosos libros de investigación y de divulgación, con muchos de tema hispánico. Tiene libros eruditos, sobre la caída del califato y sobre los geógrafos árabes (9), ediciones de textos árabes medievales como el del valenciano lbn al- ${ }^{\mathrm{C}} \mathrm{Abb}$ bâr $(10)$, colecciones de artículos y traducciones de autores hispánicos clásicos y modernos (Alejandro Casona, Arniches, Unamuno, Borges, Calderón de la Barca, Ibáñez Serrador, etc.) (11), libros de divulgación histórica (12) o traducciones de autores españoles (13).

\footnotetext{
(8) J. BESSIS, «Chekib Arslan et le facisme», Les relations entre le Maghreb et le Machrek. Des solidarités anciennes aux réalités nouvelles. Aix-en-Provence, 1984, 119-132.

(9) Essai sur la chûte du Califat Umayade de Cordoue, E. Cairo, 1948, y Târîj al-ŷugrâfiyâ wa-l-ŷugrâfiyvîn fi AlAndalus, Madrid, 1967.

(10) Al-hulla as-siyarấ li-libn AJ-C ${ }^{C}$ Abbâr. 2 vols., El Cairo, 1963.

(11) Sobre todo los artículos reunidos en los volúmenes Kutub wa-kuttâb / Libros y escritores /, El Cairo, s.a.

(12) «La conquista árabe del Mágreb» (1947) y «La gloria de Al-Andalus» (\$959), entre otras, que han tenida varias ediciones.

(13) De Garcia Lorca (1964) y de los arabistas González Palencia (1955) y García Gómez (1952).
} 
En esta actividad de escritor, Husáin Mones rindió culto a la «nostalgia de Al-Andalus», tan extendida en el mundo árabe, y escribió un libro literario, el «Viaje por Al-Andalus» (Rihlat Al-Andalus) (14). Es más breve que el de Arslán, pero también está lleno de referencias históricas, fruto de su formación y oficio de escritor. Su estilo es menos concreto (hasta se permite alguna inexactitud histórica y geográfica) y mucho más lírico.

Por eso hemos escogido un texto nostálgico y voluntariamente literario -el prólogo de la Rihlat Al-Andalus-, porque expresa no sólo los sentimientos del literato árabe sino también los de su público, al que se dirigía con el tema de Al-Andalus, seguro de que compartía sus sentimientos.

Este texto traducido no importa, pues, por sus informaciones sino por el espíritu del libro, espíritu que está también en el texto precedente de Arslán, aunque bajo un estilo más neutro. Es un espíritu de nostalgia de AlAndalus, de nostalgia del «paraíso perdido», al-firdaws al-mafqâd, que Husáin Mones intenta transformar en «paraíso prometido». Ese espíritu, en textos literarios o eruditos, informa toda la visión árabe moderna sobre la España actual y su pasado árabe.

Husáin Mones parece no haber visitado, en 1963, más que dos zonas de Sharq Al-Andalus: la ciudad de Valencia y la isla de Mallorca. Afirma que lo visitó personalmente (p. 281). Literariamente inicia su viaje por Sharq Al-Andalus a partir de Almería y Pechina, porque son ciudades comerciales y mediterráneas, significativas del esplendor comercial y marítimo de toda la región (pp. 269 ss.). Pasa luego a Valencia, de allí a Mallorca, vuelve a Valencia, otra vez a Almería y a Murcia, para terminar su capítulo sobre Sharq Al-Andalus, «el ala rota de Al-Andalus» (al-ŷnâh alKasîrl, con su visita a Zaragoza y Aragón.

No es tampoco irrelevante el resumir al menos cuáles son los temas que desarrolla sobre Sharq Al-Andalus, especialmente con referencia al País Valenciano: comenta topónimos árabes, pone de relieve el origen árabe del tribunal de las aguas de Valencia y el de los sistemas de captación y distribución de aguas con su consecuente riqueza agrícola, insiste en la riqueza comercial de la región en época árabe por los frutos de su agricultura y especialmente por las plantas medicinales, etc. Hace, finalmente, unas curiosas reflexiones sobre tres causas de por qué no se han conservado en esta región tantos monumentos árabes como en Andalucía y otras zonas de la Península: por los ataques del Cid y las batallas de musuimanes entre el siglo XI y el XIII, porque los conquistadores del XIII eran nórdicos que no apreciaban los monumentos árabes y los deshicieron para construir a su gusto europeo (catalanes, aragoneses, franceses y otros europeos) y porque la presencia y expulsión ulterior de los moriscos engendró agresividad de los cristianos contra todo lo árabe (pp. 282-283).

(14) Rihlat Al-Andalus. Hadît al-firdaws a/-maw ${ }^{c} a d$ / Viaje por Al-Andalus. Narración del paraíso prometido /, El Cairo, 1963, 445 pp. En contraportada se da como traducción española «Viaje por España», que no corresponde tan exactamente al título árabe. Lo del paraiso prometido alude directamente al «paraíso perdidow, expressión tradicional en árabe para referirse a Al-Andalus, como puede verse en el prólogo aquí traducido. 
El texto traducido y este breve resumen del capítulo sobre Sharq AlAndalus muestran bien el espíritu general y los elementos particulares de la visión tradicional árabe sobre la región.

\section{SHAKIB ARSLAN: Alicante.}

Se le llama Alicante o Alkant. Ash-Sharif Al-Idrisi dice que hay entre Denia y Alicante, yendo hacia el Occidente por el mar, setenta millas. Dice:

«Alicante es una ciudad pequeña. Está llena de construcciones. Hay un mercado y una mezquita mayor donde se hace la predicación del viernes. Su esparto provee a todos los países del Mediterráneo. Tiene frutas y legumbres en abundancia, así como higos $y$ uvas. Tiene una fortaleza muy bien defendida en la parte más alta de un monte, al que se sube con fatiga y cansancio. Además, aunque es pequeña, se construyen en ella barcos de viaje y de guerra. Cerca de esta ciudad hay una isla llamada Ibalnasa (hay que advertir, corrigiendo lo que dice AlIdrisi, que no hay aquí una isla llamada lbalnasa, sino que la isla se llama Plana. Está al sur de Alicante. No hay duda de que hay una errata en el texto y de que es una equivocación, en lugar de Planes. Depende de Alicante), que está a una milla del continente $y$ es un refugio para los barcos del enemigo. Está enfrente del cabo del An-Nadur (El Vigía). Del cabo del An-Nador a la ciudad de Alicante hay 10 millas $v$ de la ciudad de Alicante, por tierra, a la ciudad de Elche hay una jornada ligera. De la ciudad de Alicante a las gargantas de Balish (cabo Palos) hay 57 millas».

Hemos empezado citando a Al-Idrisi, pero hay que decir que la Alicante de hoy es una ciudad marítima, con una población que pasa de los 50.000 habitantes. Es capital de provincia.

Su nombre viene de la antigua Lucentum, que se piensa estaba al norte de donde está ahora, en una ensenada situada al este, llamada Huertas.

Al sur, está el cabo de Santa Pola, que los árabes Ilamaban Promontorio del Observatorio (Táraf An-Nadur).

En su parte sur está el puerto, atracadero de mar abierto, dominado por el castillo en alto, muy bien fortalecido. que los españoles llaman hoy «Santa Bárbara».

El invierno en Alicante es suave, pero el viento cambia continuamente. En verano aprieta el calor, pero siempre es más suave que en Murcia. En el 
año 1898 se hicieron conducciones de agua para Alicante. Entre los productos alicantinos hay que mencionar el vino, la pasa, la almendra y el aceite.

El puerto de Alicante es muy bonito, con un largo muelle, que tiene detrás un amplio paseo, con dos hileras de palmeras. En el centro de Alicante hay un paseo público muy bonito.

A una altura de unos 160 metros está el castillo llamado de Santa Bárbara, que tiene una vista de lo más maravilloso que la mente pueda imaginar. Desde allí los ojos contemplan las fértiles huertas de Alicante y sus costas, hasta el Promontorio del Observatorio, por un lado, y el mar, por otro. Alicante tiene un arrabal llamado arrabal de San Antón.

Al noreste de Alicante, a 17 kilómetros, hay un balneario llamado Busot, a una altitud de unos 500 metros, que se ve de todas partes. Está rodeado de un bosque de pinos. Por los alrededores de Alicante hay muchos palmerales, huertos de naranjos $y$ viñas.

Yo conocí Alicante cuando realicẻ mi viaje turístico por Al-Andalus. Veo en mis notas que llegué el 23 de agosto, a las doce del mediodía, y que pasé una noche, en la que no recuerdo que llegara a acostarme, por lo terrible del calor. A pesar de eso, tengo anotado que es una población agradable y de buen clima, gracias a la brisa, y por eso es mucho mejor que Cartagena, que había visitado el día anterior.

A la entrada de Alicante hay un bosque de palmeras que es una preciosidad. La población tiene un puerto marítimo con un hermoso muelle, con un paseo detrás que tiene dos filas de palmeras.

Encima de Alicante hay un monte coronado por una fortaleza que domina el mar.

Mi viaje a Denia fue con un ferrocarril pequeño que nos llevó hacia el norte, por la costa, junto al mar. Apenas salir, nos adentramos entre olivos y viñas. También veíamos redes de acequias, que regaban los jardines. Después pasamos por palmerales, viendo también muchos algarrobos. La llanura tiene aquí una tierra blanquecina. Está dominada por altas montañas. Al ver estas palmeras, estos algarrobos y estos olivos, no piensa uno que está en tierras europeas.

A la gente de Madrid le gusta mucho veranear en Alicante, especialmente porque el camino de Madrid a Alicante es fácil y recto. Vienen sobre todo en junio, a pesar del fuerte calor, porque su brisa marítima suaviza el calor de la tierra. Esa brisa viene de la sombra de sus frondosos árboles a las habitaciones, de forma que se está deliciosamente. Parece un oasis en medio del desierto ardiente.

El movimiento del puerto no decrece nunca, a pesar de que apriete el calor, cargando y descargando continuamente, trabajando juntos hombres y mujeres.

Las huertas de Alicante toman el agua de un riachuelo llamado Mon- 
negre. Como las aguas del riachuelo no bastaban para regar las huertas, se construyó una presa grande, de 41 metros de altura y de 42 a 57 de ancho. Con el agua del riachuelo y la construcción de la presa las huertas de Alicante se hicieron riquísimas, porque el agua con el calor hace maravillas.

Son originarios de Alicante gente sabia, cuyas biografías escribió lbn Al-Abbar.

Abu Bakr Muhámmad Ibn Ahmad Ibn Muhámmad Ibn Sufián AsSálami. Vivió en la ciudad de Tremecén. Fue discípulo de Abu Muhámmad Ibn Abi Yáfar y de Abu Al-Qásim Ibn Al-Yannán. Era una autoridad jurídica en los temas de los contratos. Tiene también cosas de poesía y de prosa epistolar. Tuvo como discípulo a Abu Abdállah Ibn Abd Al-Haqq de Tremecén. Murió en 757/1356.

Abu Zaid Abd Ar-Rahmán Ibn Alí lbn Muhámmad lbn Sulaimán AlTuyibi, natural de Alicante. Vivió en Orihuela, gobernorato de Murcia. Se le conoce con el nombre de Ibn Al-Adib. Hizo la Peregrinación el año $529 / 1134$ y luego volvió a Al-Andalus. Fue encargado de dirigir la oración y de hacer la predicación del viernes, en la mezquita mayor de Orihuela, durante mucho tiempo. Le fue ofrecida la judicatura y no quiso aceptarlo, pero le obligaron y tuvo que asumirla durante dos meses, después de los cuales pidió que se le dispensara, y se le dispensó. Era hombre de ciencia, de honor y de buenas costumbres. Al recitar el Corán tenía una voz precio$\mathrm{sa}$, de forma que cuando se le oía se veía que era hombre temeroso de Dios y que despreciaba las cosas de este mundo. Tenía un negocio y de él vivía. Era hombre elocuente y que se conmovía fácilmente, llorando y haciendo llorar cuando predicaba. Fue discípulo de Abu Muhámmad Ibn Abi Jáfar de Murcia, junto con su paisano alicantino Ahmad Ibn Muhámmad Ibn Sufián As-Sálami. Cuando cumplió con la Peregrinación, fue con su primo Abu Ahmad Muhámmad Ibn Al-Mata At-Tuyibi, el año 529/1134. Murió en Orihuela después del año 530/1135.

Abu Abdállah Muhámmad Ibn Abd Ar-Rahmán Ibn Alí Ibn Muhámmad Ibn Sulaimán At-Tuyibi. Vivió en Tremecén. Era natural de Alicante. Su padre vivió en Orihuela. Estudió las lecturas coránicas en Murcia, con su pariente Abu Ahmad Ibn Al-Mata, con Abu Al-Hayyay An-Nafsi y con Abu Abdállah Ibn Al-Fars. Viajó a Oriente, donde cumplió con la Peregrinación. Alargó su estancia por aquellas tierras. Tomó lecciones de muchos maestros en diversos estudios, más de 130, de los más famosos de Oriente Medio, entre ellos el famoso Abu Táhir As-Sálafi, que le consideró como un discípulo predilecto. Se cuenta que cuando se despidió de su maestro porque volvía al Mágreb, éste le preguntó que qué era lo que había aprendido de él. Le contestó que había tomado notas de sus lecciones en muchísimos volúmenes $y$ centenares de cuadernos. El maestro se puso contento y le dijo: serás el teólogo del Mágreb más competente en tradiciones del Profeta, si Dios quiere, porque has aprovechado mucho y bien de mis enseñanzas. El biografiado añadió: me estuvo suplicando, durante toda la 
vida, que le diera la autorización de enseñar en mi nombre lo que en realidad yo había aprendido de él.

También fueron discípulos de ellos Abu Muhámmad Al-Uthmán y su hermano Abu At-Táhir, Abu At-Táhir Ibn Awf, Abu Abdállah Ibn AlHádrami y su hermano Abu Al-Fadl, Abu Al-Qásim Ibn Yará, Abu AthThiná Al-Jarrani, Abu Al-Hafs Al-Mayánishi y otros. De los andalusíes, Abu Muhámmad Abd Al-Haqq de Sevilla, Abu Jáfar Ibn Madá, Abu Abdállah Ibn Al-Fajjar, Abu Muhámmad Al-Yasaa, Ibn Hazm y otros.

Tiene un libro muy interesante sobre sus maestros, con sus nombres por orden alfabético, que según Ibn Al-Abbar copió de su propia mano, el año 640/1242, estando en Túnez, y lo aprovecho éste para las biografías de su «Tákmila». Cuenta también que terminó en Tremecén, que tomó por patria adoptiva.

También menciona, de las obras de nuestro personaje, el programa grande y pequeño de sus enseñanzas; el diccionario de sus maestros; el tratado mayor y menor sobre los réditos, con un volumen cada uno; las virtudes de los nietos del Profeta Hassan y Husáin; el comentario de los cuarenta hadices o tradiciones del Profeta acerca de la predicación, y los cuarenta acerca de la pobreza y sus méritos; un tomo sobre el amor de Dios y otro sobre el mérito de la oración al Profeta -sobre él sea la paz-; el libro de 50 capítulos en un tomo sobre el deseo de hacer la guerra santa; dos volúmenes, uno de predicaciones y el otro de figuras de estilo; $y$ el libro de su maestro As-Sálafi.

Se cuenta de él, según Ibn Al-Abbar, que lo sabía del mencionado Abu Táhir As-Sálafi, que dijo Abu Al-Makárim Al-Abhari que había oído a Abu Al-Alá At-Tanuji en Maarra que recitaba él mismo:

Cree en un solo Dios, pues es Alá tu Señor Unico;

No reces a un montón de cabezas.

Es poco el daño y el vicio en el patio del joven, pero está más vacío que la jarra entre los comensales;

Tienen los días, noches negras y días claros, enemigos como las mujeres y los hombres.

Ojalá el niño muriese en el momento de nacer, sin mamar de su madre la parturienta.

Dijo el biografiado: escuché a nuestro maestro el Háfiz Abu Táhir (es decir, As-Sálafi\} en Alejandría lo siguiente: escuché al cadí Abu Muhámmad Al-Muwáhhid Ibn Muhámmad Ibn Abd Al-Wáhid en Testur lo siguiente: escuché a Muhámmad Ibn Alí Al-Kazaruni, el lector del Corán, en AlAhwaz lo siguiente: entramos a ver a Abu Al-Alá Al-Maarri que se marchaba de la Meca. Eramos un grupo y nos preguntó nuestros nombres, países y profesiones. Cada uno hizo su genealogía y cuando me preguntó mi profesión yo le dije: soy lector del Corán. Me dijo entonces: «Recítame una aleya del Libro de Allah, iEnsalzado sea!». Yo recité «Un día se preguntará al infierno: ¿Estás lleno? y responderá: ¿Hay alguien que tenga más?». Lloró Al-Maarri. Le pedimos que nos recitara algo de su poesía y nos recitó: 
Va el pobre y todo está contra él;

la tierra le cierra sus puertas;

Le verás errado y no tiene culpa;

verá enemistad y no sabrá el motivo;

hasta los perros cuando ven a alguien bien vestido,

son amables y mueven sus colas;

pero cuando ven a un pobre, mísero,

le ladran y le enseñan los dientes.

Nació el biografiado en Laqant la Menor alrededor del año 540/1145 y murió en Tremecén en yûmada $1 .^{\circ}$ del año 610/1213. Dice Ibn Al-Abbar: me escribieron sobre su muerte por mano de nuestro maestro Abu Zakariya Ibn Asfur de Tremecén.

Yaqut menciona Alicante en su «Diccionario de los países» y dice: "Lleva fatha en su primera letra y en la segunda; sukún en la $n$ y la $t$ con puntos diacríticos (no ta marbuta). Son dos castillos de Lérida en AlAndalus: Laqant al-Kubra y Laqant al-Sugra y están enfrentados.

Yo digo que Laqant no está en la provincia de Lérida, que está en la Frontera Superior, en la región de Zaragoza y actualmente en la región de Cataluña, ni de la de Aragón cuya capital es Zaragoza. Nos parece que hay un error en la copia y debía poner la provincia de Denia que cambió el copista por la de Lérida.

También ha podido suceder que Yaqut escribiera esto porque sabía que lbn Hud, señor de Zaragoza, Lérida y las Fronteras Superiores, se apoderó de Denia y sus contornos y expulsó a Alí lbn Muyaáhid.

\section{HUSAIN MONES}

\section{Dedicatoria}

Estos son relatos andalusíes...

Dedicados a dos nobles amigos: Ahmad Naguib Háshim y Muhámmad Hasanáin Háikal.

Dedicados a todos los que me hicieron feliz con su compañía a lo largo de este viaje. mino.

Dedicados a todos los que después de mí caminarán en este largo ca- 


\section{Prólogo}

(Paraíso) prometido, no perdido...

Visité por primera vez España en el verano de 1940, en plenas vicisitudes de la guerra. El mundo estaba revuelto...

Fui a España como a una peregrinación, para girar alrededor de nuestras sagradas piedras, que alli han quedado. Pero las circunstancias de la guerra, el poco dinero, la premura del tiempo y el mal estado de los caminos modificaron el esperado proyecto y tuve que abandonar España con toda la esperanza puesta en que volvería...

Desde entonces $\mathrm{Al}$-Andalus no ha salido nunca jamás de mi pensamiento: cuando estaba allí, porque me encontraba rodeado de sus monumentos y sus cantos; cuando estaba lejos, porque meditaba sobre su historia y me inspiraba en ella...

No sé cuántas veces fui de peregrinación hacia Al-Andalus. Pero no hubo viaje en que no sintiera que la visitaba como si fuera la primera vez. Me encontraba con ella como un enamorado, y me despedía de ella como un amante apasionado...

Cuando retornaba a vivir en mis tierras árabes, encontraba a Al-Andalus en todas las bocas: los que la habian visto soñaban con lo que habían contemplado; los que no, soñaban con el deseo de verla. Al-Andalus era para todos ellos un país árabe vivo, con su gente, sus ciudades, sus sabios, sus poetas y con su gloria que fue...

¿Cómo puede estar perdida cuando tiene toda esa presencia?

Es que está prometida, no perdida...

Prometida para los que saben que el pasado no muere sino para los que están muertos...

Prometida para todo el que sabe que la historia no conoce el ayer, el hoy o el mañana, porque es el río de la vida, que pasa hacia su término prefijado, marcado por las señales de lo invisible...

Prometida para todo el que cree en la autenticidad de esta brillante civilización árabe, que atravesó desiertos y mares, que plantó firmemente sus pies en las fauces del león, que construyó sus palacios. Subió, pero el enemigo y el destino estaban al acecho...

No, Córdoba de los califas no es una cosa del pasado. Es presente y es futuro. Mientras sigamos teniendo corazones que vivan y recuerden...

Granada de los Nasríes no es un recuerdo que pasa como las nubes y se fue. Es una bandera viva, una nube que sigue dando lluvia, conocida por toda la faz de la tierra: todos la visitan, llenándose de gozo $\gamma$ de admiración. Y la visitamos nosotros, recordando y volviendo a viejas cuentas...

Al-Andalus, toda ella, desde los montes Pirineos al estrecho de Gibraltar, es un libro de gloria eterna, que sólo puede sentir el que siente que se refiere a un pueblo que no muere... 
Prometido, no perdido...

Con este pensamiento vamos a visitar juntos Al-Andalus. No somos de los que calculan que las nostalgias son filosofía, las lágrimas sabiduría y el recuerdo de los dolores, pensamiento y purificación. Los hombres no lloran ni sufren, esperan y reflexionan. El tiempo ha pasado para nosotros, como pasó para otros. La Humanidad, a lo largo de los siglos, no ha conseguido crear nada que tenga la permanencia de las montañas; son generaciones que vienen y se van, suben y bajan, luego se van. Lo mismo sucede con todas las cosas creadas...

Loado sea Dios, el que crea las cosas y les da su destino. El es el heredero de la tierra y de cuantos hay en ella. El es el mejor de los herederos.

Madrid, mayo de 1963 